\title{
Effect of Needle Heating on the Sewing of Medical Textiles
}

\author{
Adnan Mazari
}

Citation: Mazari, A. Effect of Needle Heating on the Sewing of Medical Textiles. Polymers 2021, 13, 4405. https://doi.org/10.3390/ polym 13244405

Academic Editors: Alena Opálková Šišková and Petra Peer

Received: 18 November 2021 Accepted: 14 December 2021 Published: 15 December 2021

Publisher's Note: MDPI stays neutral with regard to jurisdictional claims in published maps and institutional affiliations.

Copyright: (C) 2021 by the author. Licensee MDPI, Basel, Switzerland. This article is an open access article distributed under the terms and conditions of the Creative Commons Attribution (CC BY) license (https:// creativecommons.org/licenses/by/ $4.0 /)$.
Department of Clothing, Technical University of Liberec, Studenstksa 2 Husova, 46117 Liberec, Czech Republic; adnan.ahmed.mazari@tul.cz

\begin{abstract}
Medical textiles, such as gowns, scrubs, and even disposable uniforms, are all stitched by sewing machines. These garments are mostly made from polypropylene (PP) and polyester due to their durability, antibacterial performance, and functionality. Demand for these garments has significantly risen in the last few years, and sewing machines are able to stitch at extremely high speeds. However, higher sewing speeds can cause burnt spots on the fabric, lower seam strength, and a decrease in production due to thread breakage. In this paper, I have deeply discussed how medical textiles lose their strength and functionality due to higher sewing speeds; this problem is often neglected due to high production demands. This research is based on PP medical gowns, stitched with polyester (PET) threads, sewn at different speeds. The experimental work is also followed by a theoretical explanation of needle heating during the stitching of medical textiles.
\end{abstract}

Keywords: medical textiles; polyester; sewing; thread

\section{Introduction}

Sewing machines are a necessity for any industry working with clothing, automobiles, footwear, medical textiles, or upholstery. Millions of products, ranging from car seat covers to medical gowns to firefighter clothing, are all stitched using industrial sewing machines. Thomas Saint is considered to have invented the practical sewing machine in 1790 [1]. It was a time of industrial revolution, and machines can greatly improve production capacity. The industrial sewing machine, used in the clothing industry, requires not only high production, but also higher sewing quality (seam strength and appearance). Typically, these machines can complete 70-90 stitches in a second [2], to keep the process as efficient as possible. It's necessary to improve each aspect of the process. Even though sewing machines can run at high speeds, human capability and technical problems during the sewing process forces users to run the machines at the much lower rate at 20-45 stitches per second. There are multiple technical reasons why it is preferable to run machines at less than half capacity, including damage to the thread, burn spots on the fabric, weaker seam strength, and many more [3-5]. The factors that cause these problems range from ambient conditions to the process parameters of sewing.

In the modern clothing production sector, there has been significant technological advancement in the last 10 years. One of the key machines used in these production units is the sewing machine, which has been made more robust, efficient, and durable. High production demand makes users run these machine so as to be as productive as possible. As a result of this high-speed production, abrasion within machine components, frictional forces, and penetration forces cause significant impacts on the overall quality of the final seam [6]. The aesthetic, as well as the functional quality, is very important for clothing, especially technical clothing.

Until now, the production of clothing by sewing machine has been labour intensive work, though sooner or later production will move towards automatic sewing. To achieve this, many aspects of the sewing process need to be closely monitored, to understand and improve them for better care-free performance [7,8]. Semi-automatic sewing machines are already on the market, though they still need constant quality management by workers [9]. 
Often, only thread breakage and aesthetic faults can be controlled [10,11], and all other damage, which may significantly reduce the seam strength, is just avoided. One of these semi-automatic sewing machines is used for jeans pockets. In this research, my focus was on the lockstitch machine due to its versatile usage and application in high strength seams, as compared to the chainstitch mechanism.

In the textile industry, the sewing process is a commonly used method to prepare final clothing. In the last few decades, not only the production, but also the quality, of the sewing has become important. Generally, multiple layers are stitched together using a sewing machine (lockstitch machine), and workers are usually paid according to work done. Therefore, it is very important for workers to produce as many garments as possible, to earn more money. Sewing machines which have the capacity to easily run at 60-100 stitches per second are one of the key solutions for workers aiming to produce and earn more. However, this has its own disadvantages. The sewing needle can reach a temperature of $\sim 150-320^{\circ} \mathrm{C}$ [11]. The hot needle damages the sewing thread and leaves undesirable spots on the fabric. The thread usually loses $35-45 \%$ of its strength $[12,13]$.

\subsection{Medical Gowns}

Different varieties of medical apparel are available on the market. Most of them are either stitched by sewing machine or bonded by ultrasonic machine. Generally, all reusable medical gowns and protective gear are stitched with sewing machines for better durability. The material used for making these garments is multiple layers of non-woven spun-bonded $\mathrm{PP}$ and PET with functional membranes. In accordance with industry standards, the stitch line is covered with protective tape to avoid leakage of spills or chemicals onto the body. The common standards for medical textiles are EN ISO 13982, EN ISO 13688, EN 13034, EN 14126, and EN 14605.

The effect of sewing speed on these medical textiles is ignored. As medical textiles were often single-use in the past, it was not very important; however, due to industrial waste of medical apparel, the majority of the new gowns are reusable, and are stitched with sewing machines. The current research is focused how sewing speed actually damages the seam strength of medical textiles.

\subsection{Basic Thermal Mechanism of Needle Heating}

The heating of the sewing needle is complicated process; the temperature abruptly rises in the first $10-13 \mathrm{~s}$ to above $130{ }^{\circ} \mathrm{C}[11,12]$, after which the rise is minor, until a steady state is attained. In each cycle of stitch formation, there are minor variations in the needle temperature during fabric penetration and withdrawal [12].

Heat is produced mainly due to friction between the needle and the thread, as well as between the needle and the fabric. Some researchers have reservations on this subject, and believe that the fabric is a source of cooling, rather than heating, whereas the other group consider it a heat source, due to the penetration and friction with the needle. Researchers from both schools of thought [12-17] have published numerous articles on this issue.

- Heat flux is generated between the outer surface of the needle and the fabric; this phenomenon depends on the needle-penetration force, withdrawal, and the frictional coefficient.

- Heat conduction between the needle and the thread is another major source of heating, and depends on the friction coefficient of the needle and thread, as well as the material parameters.

Figure 1 shows the configuration of the sewing process that is responsible for the heating mechanism [18]. 


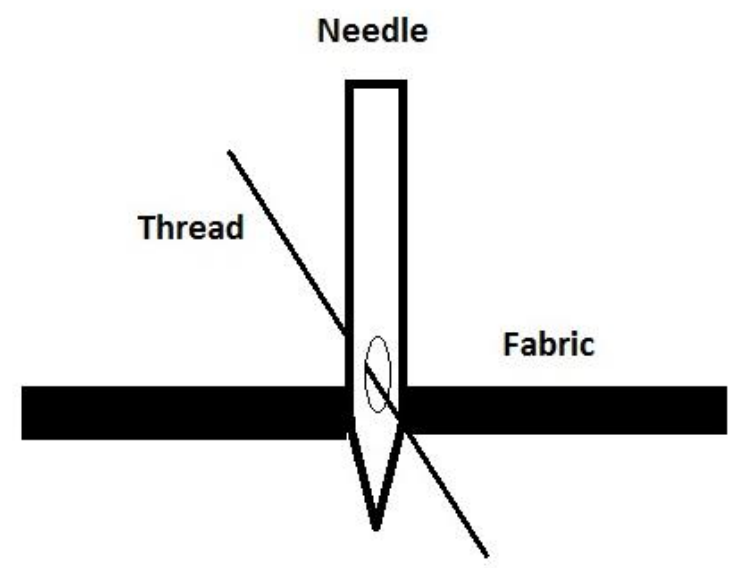

Figure 1. Sewing needle, thread, and fabric diagram [18].

\subsection{Contactless Method of Needle Temperature Measurement}

The temperature measurement of stationary objects with high emissivity levels, such as clothing, walls, and paints, is comparatively easy, while in the case of sewing needles, with small size (0.1 to $0.2 \mathrm{~cm}$ ), low emissivity (0.05-0.1) [19], and a high temperature range $\left(100-300^{\circ} \mathrm{C}\right)[18]$, it is almost impossible to obtain accurate results. In addition, the textile material and sewing thread are too close to the needle, with huge difference in emissivity, making it much harder to focus on only the sewing needle. In the past 10 years, the majority of researchers [20] used the following technique to measure the needle temperature during sewing process.

\subsection{Sewing Needle Temperature}

The temperature measurement of sewing needles is quite complicated due to their small dimension, low emissivity, and high speed during use. There are many methods and techniques used by researchers [4-9] to observe needle temperature, including infrared pyrometer, contact sensors, and sensitive waxes/colors, etc. Moreover, with improved knowledge of sewing needle heating, there are many improvements $[21,22]$ to be made in the design of needle, as well as the use of lubricants and coatings, which can help to decrease needle temperature.

\section{Materials and Methods}

For this research, the most common medical-textile material and sewing thread was used to determine the effect of sewing processes on seam strength and needle temperature.

The following fabric as described in the Table 1. was used for the experiment.

Table 1. Fabric details.

\begin{tabular}{ccccc}
\hline Material & Manufacturing Technique & Weight $\left[\mathbf{g} / \mathbf{m}^{\mathbf{2}}\right]$ & Thickness [mm] (S.D) & Layers Used \\
\hline $\mathrm{PP}$ & $\begin{array}{c}\text { Spun-bonded melt-blown } \\
\text { polypropylene }\end{array}$ & 75 & $1.2( \pm 0.15)$ & 3 \\
\hline
\end{tabular}

The selection of this material was mainly due to its common usage in the production of medical gowns; as well, this material is preferred for reusable gowns in the medical field. The thread which was used in the sewing of these gowns is listed below in Table 2.

Table 2. Thread details.

\begin{tabular}{cccc}
\hline Material & Twist & Count [tex] & Producer \\
\hline PET & Z/S & 40 & Amman $^{\circledR}$ (Liberec, Czech Republic) \\
\hline
\end{tabular}


Three layers of fabric were stitched together, for $30 \mathrm{~s}$ each time, at different sewing speeds, and properties such as tensile strength of the thread, needle temperature, and aesthetic damage to the textile were recorded before and after the sewing process. The stitch length, needle, and ambient conditions were kept constant for all experiments.

Conditions for all experiments were kept constant at $26^{\circ} \mathrm{C}$ and $65 \% \mathrm{RH}$. The following machine and accessories were used for the experiment.

- $\quad$ Lockstitch machine (Brother Company, Berlin, Germany DD7100-905).

- $\quad$ Thermocouple by Omega (K type 5SC-TT-(K)-36-(36)).

- Thermocouple by Omega-wireless device and receiver (MWTC-D-K-868).

- $\quad$ Needles (Groz-Beckert, Stuttgart, Germany 100/16) R-type.

Initially, the medical-textile material was stitched at different sewing speeds, and the needle temperature was recorded. The methodology used to measure needle temperature was the inserted thermocouple technique, in which a thermocouple is embedded in the needle to obtain an accurate needle temperature; this technique is explained by the authors of [23].

In this method as shown in Figure 2. for measuring sewing needle temperature, a thermocouple, by Omega (K type 5SC-TT-(K)-36-(36)), was inserted into the groove of the sewing needle and soldered. The thermocouple was located near the eye of the needle, to measure the exact needle temperature, and the temperature was measured at different sewing speeds. This method proved to be very efficient, as it provided continuous changes in needle temperature every second, and it had a low standard deviation.

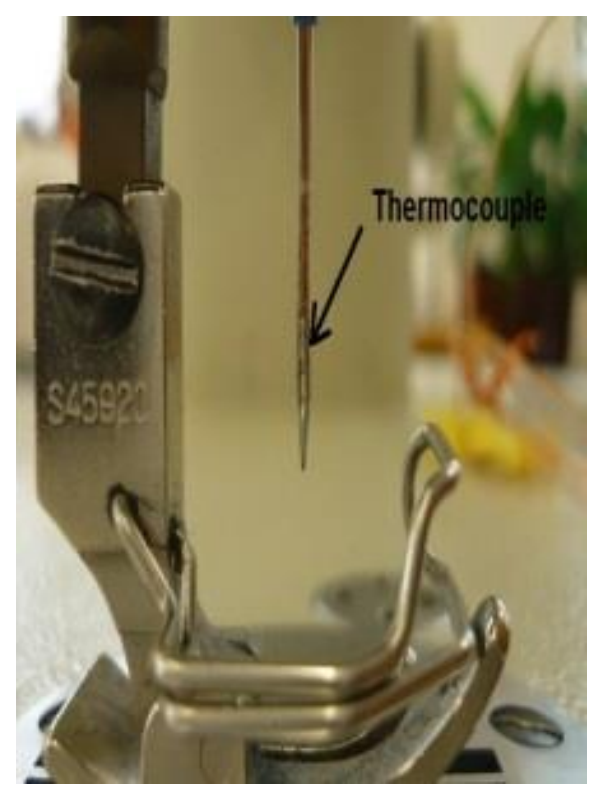

Figure 2. Thermocouple embedded in the needle.

Subsequently, to measure the strength of the threads, the sewing thread was taken out of the seam and the tensile strength of the final thread, after stitching, was compared with its parent strength. The thread was pulled out of the seam by carefully cutting the bobbin thread, without disturbing the twist.

\section{Results and Discussion}

A continuous $30 \mathrm{~s}$ of sewing was performed, keeping all conditions similar for the duration of the experiment. The results of the needle temperature measurement are shown in Figure 3. 


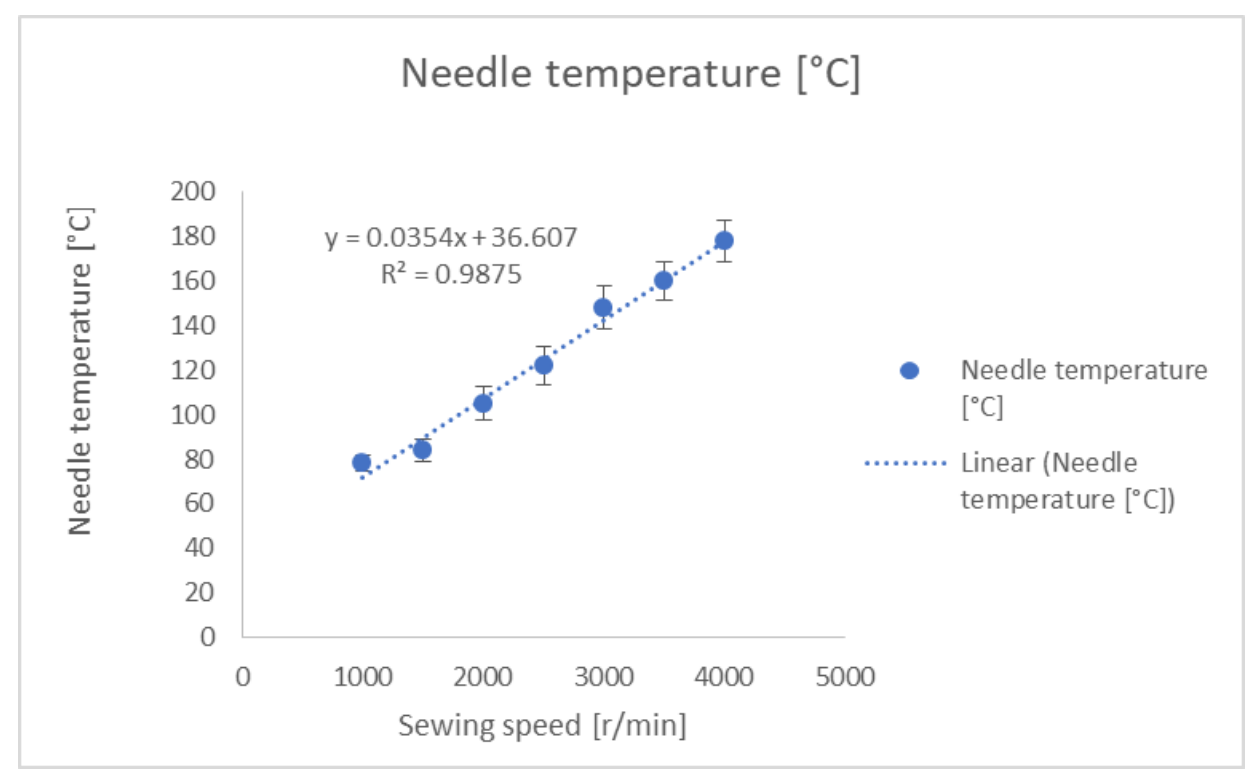

Figure 3. Sewing needle temperature at different sewing speeds.

At a sewing speed of $3000 \mathrm{r} / \mathrm{min}$, the fabric started to show black spots due to the high temperature of the needle. It can be also seen from the Figure 3 that there was a linear increase in sewing needle temperature with respect to machine speed. Polyester thread has a higher melting temperature than PP, and therefore may not melt; nonetheless, this high temperature causes structural changes to the polymer.

The tensile strength of the sewing thread was measured using ASTM 2256 standards. The Figure 4 shows the obtained results.

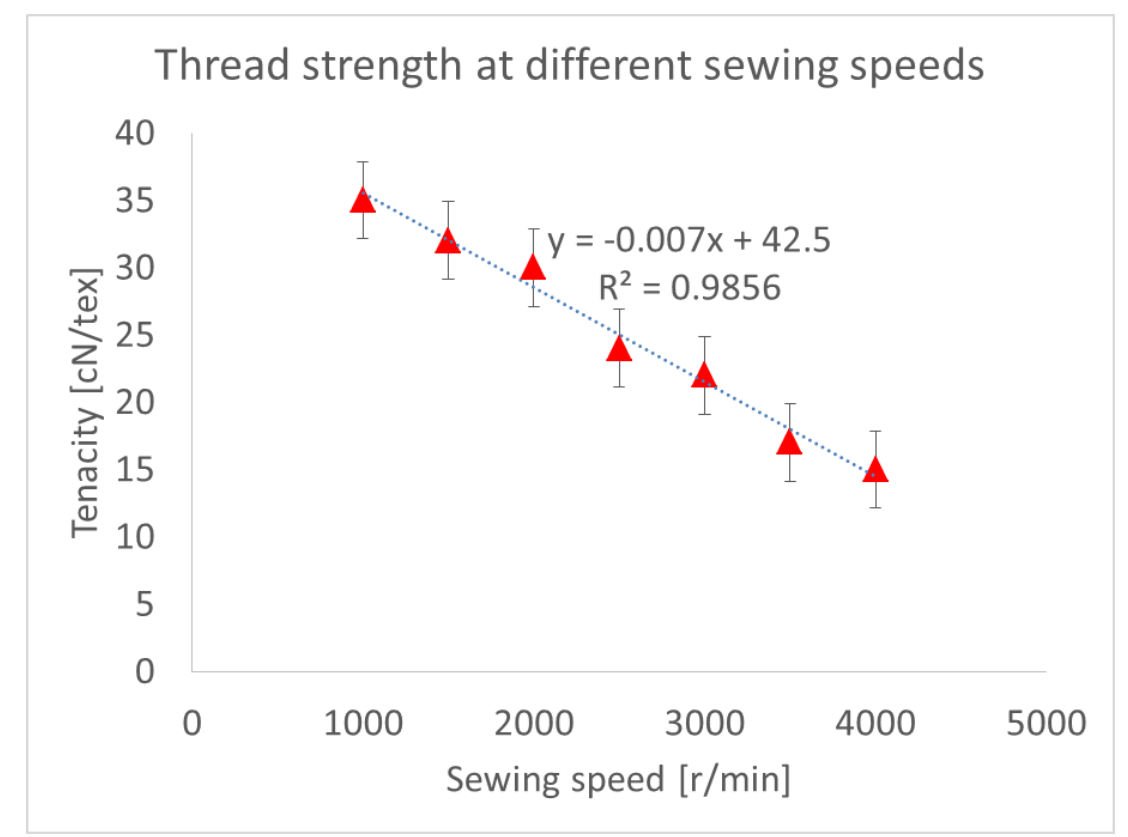

Figure 4. Tensile strength of thread at different sewing speeds.

It can be clearly seen that, at higher sewing machine speeds, there was a significant decrease in thread strength, which may have been due to abrasion, or the high temperature of the needle. There was negative linear relationship between sewing speed and thread strength. It was also alarming that, at speeds of $3000 \mathrm{r} / \mathrm{min}$ and higher, the thread lost $50 \%$ of its original strength. 
Figures 3 and 4 show that, with higher speeds, there is a rise in needle temperature and a decrease in the tensile strength of the thread. The highest temperature, $187^{\circ} \mathrm{C}$, was recorded at a speed of $4000 \mathrm{r} / \mathrm{min}$, during which the sewing thread lost more than $50 \%$ of its original strength. To explain this needle heating for sewing thread a theoretical model was developed, which is improved work of the author himself.

\section{Theoretical Analysis}

Different methods and approach have been used by researchers in the past, and a major conflict is whether or not the fabric is the source of heating; different schools of thought exist. In my approach, the analytical model is considered, which requires less computation, has higher accuracy, and could be easily used by industrial partners in the future. In this model the assumptions listed below are made:

1- The needle, thread, and fabric are all at room temperature.

2- The needle is a cylinder with the same material composition throughout.

3- $\quad \lambda_{N}$ is the thermal conductivity of the needle material, and is significantly higher than that of the sewing thread $\lambda_{y}$ and fabric $\lambda_{F}$. Here it is discreetly assumed that both the thread and fabric have lumped thermal properties, i.e., each has unchanging thermal conductivities, represented by single value.

4- The thread and textile fabric are considered homogenous, with constant thermal conductivity value throughout.

5- Radiation heat can be neglected due to the small size of the needle and a smaller contribution compared to other factors.

6- In this model, it is estimated that friction heat is assumed as $Q=F^{*} v$ [18], where $\mathrm{F}$ is friction force and $v$ is the relative velocity of the two surfaces.

7- $\quad \gamma$ is the ratio determining the amount of heat distribution when two materials rub together. Partition ratio is calculated, using the Charron's relation [24], as:

$$
\gamma=\frac{1}{1+\xi_{N}}
$$

where $\xi_{N}=\frac{b_{i}}{b_{N}}, N$ denotes the needle, $i$ denotes the other rubbing material in contact, and $b$ is the thermal absorptivity of the respective materials. The calculated value is given as $b=\sqrt{(\rho * C * \lambda)}$, where $\rho$ is the density of the material, $C$ is the specific heat of the material, and $\lambda$ is the thermal conductivity.

An analytical approach was used to predict needle temperature, assuming that heat is produced during the sewing process as a result of needle-thread and needle-fabric friction. In this analysis, a steady-state condition is considered, in which the amount of heat generated by friction exactly equals the amount of heat lost by the needle. The complex shape of needle is neglected, and it is treated as a uniform cylinder. as [18]:

The heat generated due to friction between the needle and the fabric can be expressed

$$
Q_{F N}=\gamma_{F N} * \mu_{F N} * F_{F N} * v_{F N}
$$

The heat generated due to friction between the sewing thread and the surface of needle can be expressed as:

$$
Q_{Y N}=\gamma_{Y N} * \mu_{Y N} * T_{y} * \cos \theta * v_{Y N}
$$

where the legends are described in Table 3.

Maximum needle speed was found to have a linear function of machine speed with the multiplier constant $C_{F N}=0.0008$.

The total heat gain by the needle is finally:

$$
Q_{N}=Q_{F N}+Q_{Y N}
$$


From the 1st law of thermodynamics in a closed system,

$$
Q=m * C_{N} *\left(T-T_{i}\right)
$$

where $m$ is the mass of the needle, $C_{N}$ is the specific heat of needle, $T$ is the final temperature of needle, and $T_{i}$ is the initial temperature of needle

From Equations (1)-(5), following relation is obtained:

$$
m * c_{N} *\left(T-T_{N}\right)=\gamma_{F N} * \mu_{F N} * F_{F N} * v_{F N}+\gamma_{Y N} * \mu_{Y N} * T_{y} * \cos \theta * v_{Y N}
$$

Equation (6), for a more precise result, should be solved by calculating it numerically over time, as many of the variables present in Equation (6) are complex functions of time. However, in order to simplify the calculations, the maximum value of $F_{F N}$ and $T$ are considered here for the prediction of maximum needle temperature. Similarly, the maximum relative speed between the needle and sewing thread is used as $v_{Y_{N}}$. As an additional approximation, both $v_{F N}$ and $v_{Y N}$ are stated as proportional to the machine speed $v_{M}$. If $C_{F N}$ and $C_{Y N}$ are the two coefficients of these proportionalities, respectively, then it can be obtained from Equation (6) that:

$$
T-T_{i}=B * v_{M}
$$

where " $B$ " is:

$$
B=\frac{1}{m \times c_{N}} *\left\{\gamma_{F N} * \mu_{F N} * F_{F N} * C_{F N}+\gamma_{Y N} * \mu_{Y N} * T * \cos \theta * C_{Y N}\right\}
$$

Thus, Equation (8) shows that the highest needle temperature is a linear function of machine speed. An estimate of maximum needle temperature, from machine speed, is possible if the parameter $B$ can be calculated using Equation (8). The value of the symbols are described in Table 4.

It can be seen from Figure 5 that the theoretical and experimental results both show a linear trend of increasing needle temperature. A difference in absolute values is possible, as in all theoretical models many assumptions are made to simplify the model. The analytical approach can be solved without complex simulation.

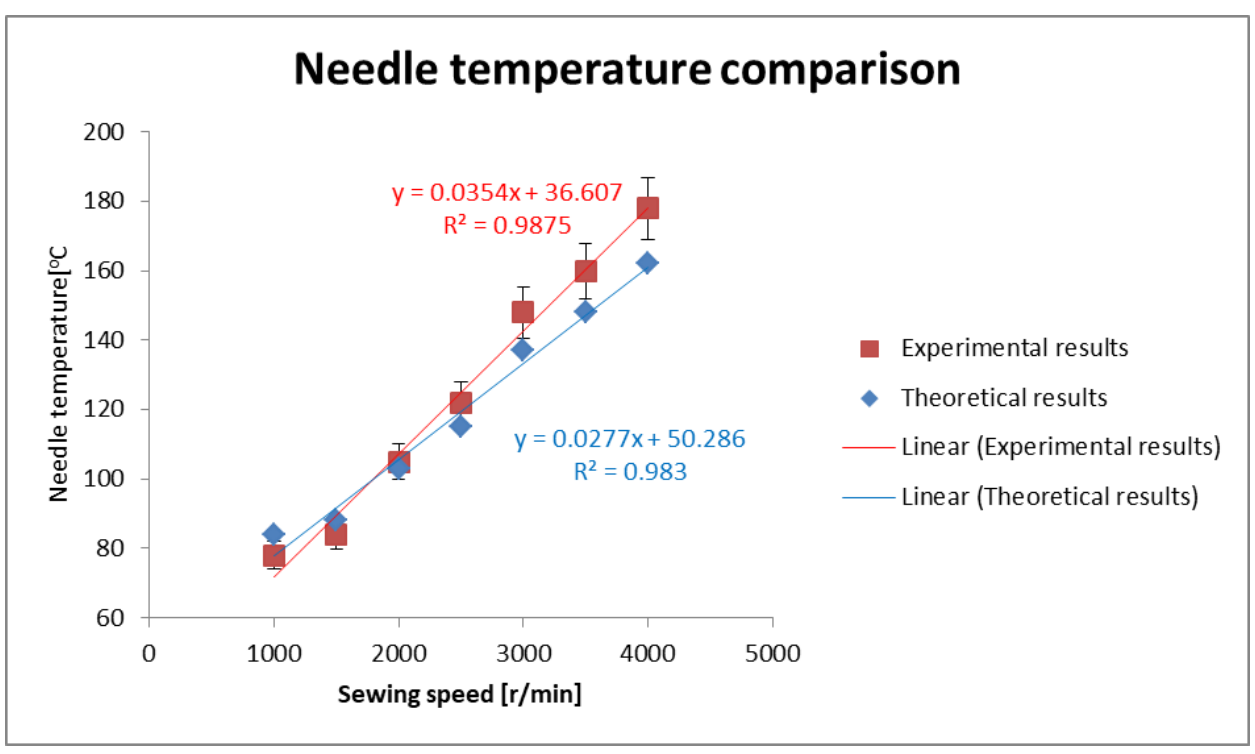

Figure 5. Comparison of experimental and theoretical results. 
Table 3. Legend of equations.

\begin{tabular}{cc}
\hline$\gamma_{N Y}$ & Partition ratio of heat gain between needle and thread using Charron's relation. \\
\hline$\gamma_{F N}$ & Partition ratio of heat gain between needle and fabric using Charron's relation. \\
\hline$\mu_{Y N}$ & Coefficient of friction between needle and sewing thread. \\
\hline$\mu_{F N}$ & Coefficient of friction between fabric and sewing thread. \\
\hline$T_{y}$ & Maximum tension of sewing thread during sewing cycle. \\
\hline$\theta$ & Angle of sewing thread with respect to the needle. \\
\hline$v_{F N}$ & Velocity of needle with respect to the fabric. \\
\hline$F_{F N}$ & Needle penetration force with respect to the fabric. \\
\hline$v_{Y N}$ & Velocity of thread with respect to the needle. \\
\hline
\end{tabular}

Table 4. List of symbol and units.

\begin{tabular}{lccc}
\hline \multicolumn{1}{c}{ Property } & Symbol & Value & Unit \\
\hline Heat partition ratio (fabric \& needle) [24]. & $\gamma_{N F}$ & 0.945 & - \\
\hline Heat partition ratio (thread \& needle) [24]. & $\gamma_{N Y}$ & 0.958 & - \\
\hline Density thread [25]. & $\rho_{y}$ & 1400 & $\mathrm{~kg} / \mathrm{m}^{3}$ \\
\hline Specific heat of thread [26]. & $C_{y}$ & 750 & $\mathrm{~J} / \mathrm{kgK}$ \\
\hline Thermal conductivity of thread [26]. & $\lambda_{y}$ & 0.15 & $\mathrm{~W} / \mathrm{mK}$ \\
\hline Density of fabric [27]. & $\rho_{f}$ & 920 & $\mathrm{~kg} / \mathrm{m}^{3}$ \\
\hline Specific heat of fabric [26]. & $C_{f}$ & 1700 & $\mathrm{~J} / \mathrm{kgK}$ \\
\hline Thermal conductivity of fabric [experimental]. & $\lambda_{f}$ & 0.04 & $\mathrm{~W} / \mathrm{mK}$ \\
\hline Density of needle [28]. & $\rho_{n}$ & 7850 & $\mathrm{~kg} / \mathrm{m}^{3}$ \\
\hline Specific heat of needle [28]. & $C_{n}$ & 523 & $\mathrm{~J} / \mathrm{kgK}$ \\
\hline Thermal conductivity of needle [28]. & $\lambda_{n}$ & 40 & $\mathrm{~W} / \mathrm{mK}$ \\
\hline Friction coefficient of needle and thread [experimental value]. & $\mu_{t}$ & 0.3 & - \\
\hline Friction coefficient of needle and fabric [experimental value]. & $\mu_{f y}$ & 0.21 & - \\
\hline Tension thread maximum [29,30]. & $T_{y}$ & 1.05 & $\mathrm{~N}$ \\
\hline Needle velocity [experimental value]. & $v_{N}$ & 2.3 & $\mathrm{~m} / \mathrm{s}$ \\
\hline $\begin{array}{l}\text { Machine speed (to be used with constant to balance } \\
\text { the equation). }\end{array}$ & $V_{m}$ & $1000-4500$ & $\mathrm{r} / \mathrm{min}$ \\
\hline Needle and thread angle of contact [31]. & $\theta$ & 60 & $\mathrm{o}$ \\
\hline $\begin{array}{l}\text { Frictional normal penetration force to needle from fabric } \\
\text { [experimental value]. }\end{array}$ & $F_{F N}$ & 2.5 & $\mathrm{~N}$ \\
\hline
\end{tabular}

\section{Conclusions}

The process of sewing is very important for any clothing or wearable textile company. Any improvement in the process can provide huge economic benefits, including higher productivity. Generally, the strength of the seam, or sewing thread, used in the stitching of medical textiles is neglected. As the demand for reusable medical textiles, such as gowns, is increasing, it is important to understand the performance parameters of the seams and sewing threads used in the stitching of medical textiles. The focus of this research was the theoretical and experimental explanation of how needle heating due to machine speed can impact the strength of medical textiles. This work provides in-depth knowledge of the sewing process, including possible limitations and improvements to be made in the textile industry. This work is also beneficial for researchers, as it provides a theoretical 
analysis of sewing needle temperature measurement. If cooling accessories are not used, it is advisable to run the sewing machine at a speed of $2000 \mathrm{r} / \mathrm{min}$ or lower.

Funding: This work was supported by the Ministry of Education, Youth, and Sports in the Czech Republic under the "Inter Excellence-Action programme" within the framework of the project "Mi-cro-struCtural imaging as a Tool for modelinG fibrOus materiALS ( $\mu$-CT GOALS)" (registration number LTAUSA18135).

Institutional Review Board Statement: Not applicable.

Informed Consent Statement: Not applicable.

Data Availability Statement: Not applicable.

Acknowledgments: This work was supported by the Ministry of Education, Youth, and Sports in the Czech Republic under the "Inter Excellence-Action programme" within the framework of the project "Micro-struCtural imaging as a Tool for modelinG fibrOus materiALS ( $\mu$-CT GOALS)" (registration number LTAUSA18135).

Conflicts of Interest: The authors declare no conflict of interest.

\section{References}

1. Graham, F. A Brief History of the Sewing Machine. International Sewing Machine Collectors' Society. Available online: http:/ / ismacs.net/sewingmachine_history.html (accessed on 1 October 2021).

2. Maja, J.; Goran, D. The influence of the sewing speed and fabric thickness on sewing machine stitch formation parameters. Adv. Technol. 2017, 6, 72-77.

3. Carvalho, M.; Carvalho, H.; Silva, L.F. Problems relating to sewing. In Joining Textiles; Woodhead Publishing Series in Textiles; Jones, I., Stylios, G.K., Eds.; Woodhead Publishing: Duxford, UK, 2013; pp. 149-174.

4. Nayak, R.; Padhye, R. Automation in Garment Manufacturing; Woodhead Publishing: Duxford, UK, 2018; pp. 1-290.

5. Kumar, C.S.S.; Ramachandralu, K. Study on Relationship between Sewing Thread Tension and Fabric. Eur. J. Adv. Eng. Technol. 2015, 2, 105-107.

6. Mazari, A.; Zhu, G.; Havelka, A. Sewing needle temperature of an industrial lockstitch machine. Ind. Text. 2014, 65, 335-339.

7. Gribaa, S.; Amar, S.B.; Dogui, A. Influence of sewing parameters upon the tensile behavior of textile assembly. Int. J. Cloth. Sci. Technol. 2006, 18, 235-346. [CrossRef]

8. Juciene, M.; Vobolis, J. Influence of fabric external friction force and certain parameters of a sewing machine upon stitch length. Mater. Sci. 2004, 10, 101-104.

9. Mazari, A.; Havelka, A.; Wiener, J.; Rozek, Z. A study on DLC-coated industrial lockstitch sewing needle. Ind. Text. 2015, 66, 43-47.

10. Lee, S.; Rho, S.H.; Lee, S.; Lee, J.; Lee, S.W.; Lim, D.; Jeong, W. Implementation of an automated manufacturing process for smart clothing: The Case Study a Smart Sports Bra. Processes 2021, 9, 289. [CrossRef]

11. Gersak, J. Analysis of loading of the thread in the process of stitch forming. Tekstil 1987, 36, 481-489.

12. Liasi, E.; Du, R.; Simon, D.; Dimitrejevic, J.; Liburdi, F. An experimental study of needle heating in sewing heavy materials using infrared radiometry. Int. J. Cloth. Sci. Technol. 1989, 11, 300-314. [CrossRef]

13. Hersh, S.; Grady, P. Needle heating during high speed sewing. Text. Res. J. 1969, 39, 101-120. [CrossRef]

14. Yukseloglu, M.; Citoglu, F.; Catinkaya, B. A study on the needle heating in polyester blend upholstery fabrics. Ind. Text. 2013, 63, 246-253.

15. Li, Q.; Liasi, E.; Simon, D.; Du, R. Heating of industrial sewing machine needles: FEA model and verification using IR radiometry. In Thermosense XXI; International Society for Optics and Photonics: Bellingham, WA, USA, 1999; Volume 3700, pp. $347-357$.

16. Mazari, A.; Bal, K.; Havelka, A. Prediction of needle heating in an industrial sewing machine. Text. Res. J. 2016, 86, 302-310. [CrossRef]

17. Khan, R.; Hersh, S.; Grady, P. Simulation of needle-fabric interaction in sewing operation. Text. Res. J. 1970, 41, 489-497. [CrossRef]

18. Li, Q.; Liasi, E. A study on the needle heating in heavy industrial sewing part-1. Int. J. Cloth. Sci. Technol. 2001, 13, 351-367. [CrossRef]

19. Laughlin, R. Needle temperature measurement by infrared pyrometry. Text. Res. J. 1963, 33, 35-39. [CrossRef]

20. Sondhelm, W. Causes of seam damage: Needle heating. J. Text. Inst. 1953, 44, 580-585. [CrossRef]

21. Gurarda, A.; Yukseltan, E.; Kaplangiray, B.M.; Kanik, M. The effects of various lubricants on the friction properties of sewing threads. Text. Res. J. 2008, 83, 1273-1282. [CrossRef]

22. Groz-Beckert Newsletter. Available online: https://www.groz-beckert.com (accessed on 1 April 2021).

23. Mazari, A.; Havelka, A.; Hes, L. Experimental techniques for measuring sewing needle temperature. Textile Ve Konfeksiyon 2014, 24, 111-118.

24. Charron, F. Partage de la Chaleur Entre Deux Corps Frottants; Blondel La Rougery: Paris, France, 1943. 
25. James, S. Lange's Handbook of Chemistry, 16 ed.; McGraw-Hill Professional: New York, NY, USA, $2005 ;$ pp. $2758-2807$.

26. Thermal Conductivity. Available online: http://www.engineeringtoolbox.com/ (accessed on 20 October 2021).

27. Sakthivel, J.C.; Mukhopadhyay, S.; Palanisamy, N.K. Some Studies on Mudar Fiber. J. Ind. Text. 2005, 35, 63-76. [CrossRef]

28. ASTM. International 10th ed. Metals Handbook. Available online: http:// products.asminternational.org/hbk/index.jsp (accessed on 24 October 2020).

29. Rengasamy, R.; Wesley, D. Study on Dynamic Needle Thread Tensions in a Single Needle Lock Stitch (SNLS). Fibers Polym. 2014, 15, 1773-1778. [CrossRef]

30. Rudolf, A.; Geršak, J.; Ujhelyiová, A.; Smole, M.S. Study of PES Sewing Thread Properties. Fibers Polym. 2007, 8, 212-217. [CrossRef]

31. Li, Q.; Liasi, E. A study on the needle heating in heavy industrial sewing-part II. Int. J. Cloth. Sci. Technol. 2001, 13, 87-105. [CrossRef] 